Journal of Science
http://dergipark.gov.tr/gujs

\title{
A New Mathematical Model for the Integrated Solution of Cell Formation and Part Scheduling Problem
}

\author{
Yeliz BURUK SAHIN ${ }^{1, *}$ (D) , Serafettin ALPAY ${ }^{1}$ \\ ${ }^{I}$ Eskisehir Osmangazi University, Department of Industrial Engineering, 26480,Eskisehir, TURKEY
}

\author{
Highlights \\ - The paper focuses on an integrated cell formation and part scheduling problem. \\ - The objectives of the proposed model are the minimization of EEs in cells and makespan of the jobs. \\ - The validity of the model is tested on numerical examples that are derived from the literature. \\ - The developed mathematical model improves the overall system performance.
}

Article Info

Received: $17 / 10 / 2018$

Accepted: 20/06/2019

\section{Keywords}

Cellular manufacturing

systems

Part scheduling

Mathematical model

Exceptional elements

\begin{abstract}
In a cellular manufacturing system, three important decisions are to form cells, design the layout of cells, and schedule of parts in the cells. Most of the studies in this area have discussed these decisions separately and independently. However, for general system performance, it is important to consider these decisions in relation to each other, and integrated solutions are needed. But few studies include that two or more decisions are handled together. In this paper, a new mathematical model considers decisions both cell formation and part-scheduling in cells together is proposed. The objective function is designed in integrated manner and includes two objectives to minimize together. These objectives are to minimize the exceptional elements and makespan of the jobs. Numerical examples are provided in the paper to show that the model is valid and it can be applicable as practically. The test data are derived from the related literature and solved by GAMS software CPLEX solver. The results show that the performance of the cellular manufacturing systems in terms of formation of cells and scheduling of parts can be significantly improved by the proposed multi objective mathematical model.
\end{abstract}

\section{INTRODUCTION}

The Cellular Manufacturing System (CMS) is a production system which is based on the philosophy of Group Technology. It enables to consider similarities of parts and available machines and to form possible manufacturing cells in order to process parts on dedicated machines [1]. CMS includes Cell formation (CF), Cellular Layout (CL), Part Scheduling in Cells (CPS) and Resource Allocation (RA) decisions. CF implies grouping all parts of a family with similar sequence of operations within a machine cell because of the similarity of manufacturing processes required. The most leading objectives are maximizing utilization of the machines within a cell, minimizing intercellular movement number or cost of parts and exceptional elements (EE). An EE occurs when a production requirement necessitates a part movement between cells [2]. CL refers to layout of machines within each cell (intra-cell layout) and laying out cells within a shop floor (inter-cell layout). CPS deals with the scheduling of parts within each cell after forming of the cells in a manufacturing environment by aiming to optimize some objectives like minimizing makespan, minimizing total weighted tardiness. RA decisions include assigning tools, human and material resources into cells. 
Although the decisions related to CF, CL, CPS and RA are correlated with each other, they are mostly considered separately in the literature. Among these decisions, CF and CPS are two important and related in the simultaneous design of CMS. Most of the models in the literature have been developed to take advantage of the integrated solution approach and improve overall performance of the system. Arkat et al. [3] mentioned that considering CF, CL, and CS decisions in a simultaneous manner can significantly improve the performance of the Cellular Manufacturing Systems. This is because the sum of individual system performances is smaller than the total system performance. According to $\mathrm{Wu}$ et al. [4] CF and CS are interrelated and the solutions are interdependent. Solutions to improve individual objectives do not provide satisfactory solutions for the overall system performance level. It is because these problems are sub problems of the cellular manufacturing system design procedures. The integrated nature of these sub problems lead to not guaranteed solutions satisfying other objective. So, in this study integrated consideration of CF and CPS decisions are considered. In this way, our study fills a gap offering an integrated mathematical model that considers maximum completion time and the number of exceptional elements, simultaneously.

\section{LITERATURE REVIEW}

There are many studies have paid attention to CF decisions [5-8] but, relatively few works consider two or more CMS decisions together such as CF \& CL [9,10]; CF, CL \& and operator assignment [11-13]; CF, CL \& CS [14]. As CF and CPS decisions are correlated, integrated solutions consider them together rather than considering separately are critical to increase the effectiveness of the production system. The previous researches devoted to CPS study on scheduling either in flow line cell or job shop cell [15]. Most of them have focused on scheduling in a flow line cell [16-19]. On the other hand, relatively less studies deal with job shop cell scheduling [20-23]. In this study, we addressed our problem in flexible job shop cells. The flexible job shop scheduling problem (F-JSSP) is a special form of a classical job shop scheduling problem (JSP) [24]. In the recent studies of F-JSSP, Fattahi et al. [25] have proposed a new approach for F-JSSP with overlapping in operations. Moradi et al. [26] have considered integrated F-JSSP by considering the minimization of the makespan and the minimization of the system non-availability for some special parts. Ozguven et al. [24] have addressed an improved type of F-JSSP by considering flexibility and setup times. Additionally, they have given a general view of the models and approaches for F-JSSP.

Although there aren't many studies on CF problem together with CPS an increasing trend on this area appears in the recent literature. In this study, we deal with the integrated problem of CF and CPS in the flexible job shop environment. So, the studies taking into account this integrated approach are reviewed in details and given as follows. Papaioannou and Wilson [27] have considered an integer mathematical model which is capable of assigning parts and machines together to the cells. The objectives are minimizing costs of intercellular movements, setups and revisiting the cells. Additionally, fuzzy models are developed to simulate the uncertainty environment of manufacturing cells. Wang et al. [28] have studied CF together with CPS and developed a model which has nonlinear structure considering multiple type of each machines and parts. Ghezavati and Saidi-Mehrabad [29] have proposed a stochastic mathematical model to consider $\mathrm{CF}$ and CPS decisions, concurrently. Their model can trade of between subcontracting and scheduling costs. Kesen et al. [30] have presented a multi-objective mixed integer programming formulation to minimize makespan and total traveling distance for solving job shop scheduling model in virtual cells in order. To enhance the system's agility, machines that have the similar processing abilities are located different areas in this system. Dalfard [31] has presented a new mathematical model for forming dynamic cell problem in a cellular manufacturing system. Their objective is to allocate intercell movements to the shortest distances. Tang et al. [32] have presented an integrated approach for CF and CPS. Their approach includes a heuristic with lagrangian relaxation decomposition method. Li et al. [33] have studied inter-cell scheduling by considering single and/or batch processing machine types. This study also takes into account flexible intercell processing routes, inter-cell transfer time, and setup time and aims to minimize the makespan. Rafiei et al. [34] have developed a mixed integer nonlinear model for CF and job scheduling. They aim to reduce the operation and carrying costs. Zeng et al. [35] have developed a nonlinear mathematical model considering CPS problems with the objective of minimizing of makespan. Halat and Bashirzadeh [15] have presented a mathematical model which has linear structure for CPS problem and used a concurrent approach 
to schedule jobs in cells. Deliktas et al. [36] have presented new nonlinear multi objective models for flexible job shop scheduling problem in cellular environment. Mainly, exceptional parts, sequence dependent family setup times, intercellular transportation times and recirculation have been considered. Feng et al. [37] have addressed the CPS problem that aims to minimize the makespan and balance the total workload in a dynamic environment.

From the previous related researches, one can say that this study is the first study that considers the integrated solutions of CF and CPS problems to improve overall system performance with the objectives of $\mathrm{EE}$ and the makespan in flexible job shop environment and proposes a linear mathematical model. Makespan is selected for the optimization criterion for scheduling, because it intends to increase utilization of all machines by reducing of idle time. Minimizing makespan will also minimize machine idle time [38]. Exceptional part term is also used in the objective function of the model, because of the fact that it is hard in practice to allocate all machines required for producing a part in a cell. Moreover, it is not always possible to purchase many machines because of economic reasons.

Table 1. Literature review of CF and CPS problems

\begin{tabular}{|c|c|c|c|c|c|c|c|c|c|c|}
\hline \multicolumn{3}{|c|}{$\begin{array}{c}\text { Problem } \\
\text { Constraints }\end{array}$} & \multicolumn{6}{|c|}{ Objective Functions } & Condition & $\begin{array}{l}\text { Optimization } \\
\text { Software }\end{array}$ \\
\hline 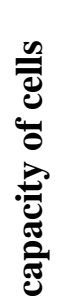 & 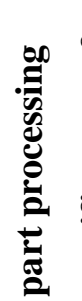 & 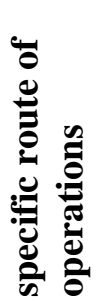 & 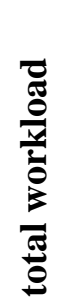 & 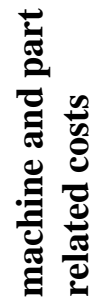 & 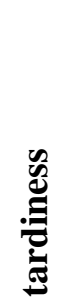 & 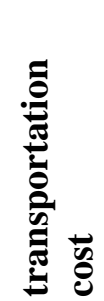 & 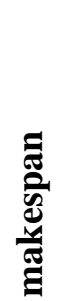 & 工 & & \\
\hline
\end{tabular}

Source

Dalfrad (2013)
Tang et al. (2014)
Zeng et al. (2015)
Halat and
Basirzadeh (2015)
Li et al. (2016)
Rafiei et al.
(2016)

Deliktas (2017)

Feng et al. (2018)

This Study

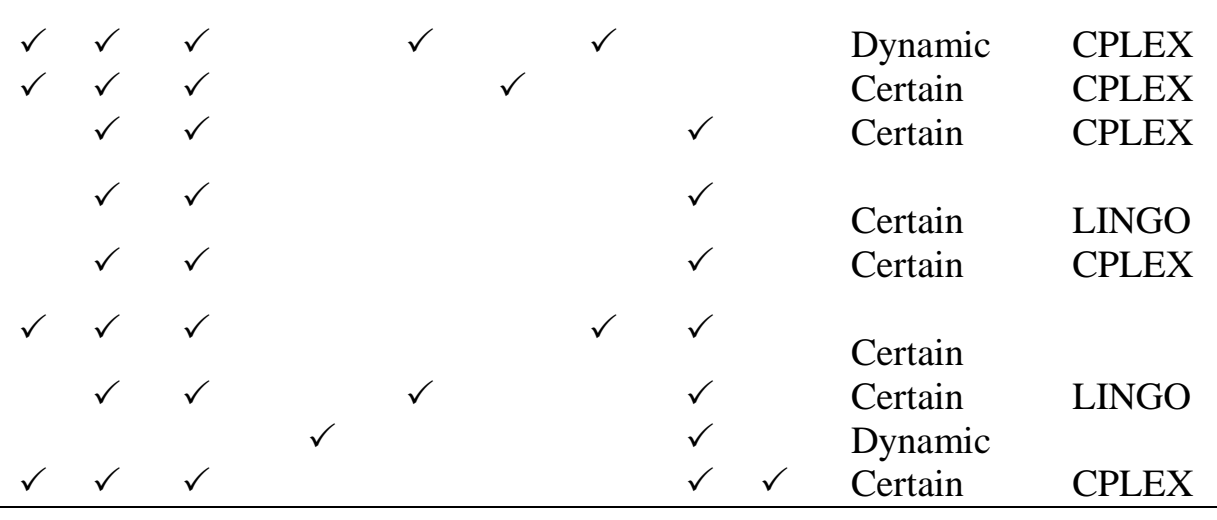

As seen from Table 1, most of the studies considering CF and CPS decisions simultaneously, have used makespan as an objective. Besides, there is no study considers EE as an objective or part of objective. On the other hand, EE is a notable part of the effectiveness of a CF problem. Therefore, it was considered as part of the objective function in this study. The objective function in this form is multi-objective and original and aims at optimizing EE and makespan together. In this way, compared to individual and independent optimization of the sub-objectives, the overall system performance can be further improved.

\section{MATHEMATICAL MODEL FORMULATION}

A new mathematical model for the above mentioned integrated problem is proposed in here.

\section{Assumptions}

Each machine can process one part at a time and process different parts. There is one machine available in a machine type. A machine can be located to just one cell. A part can be assigned to one cell only. If a part is assigned to the machines in more than one cell then it is named an exceptional part. Each machine processes only one operation on each part, i.e. no re-entry is allowed. Each part has a specific machine 
route of operations. Part processing times are known and constant. No preemption is allowed. Processing times also include sequence independent setup times. The release time of all parts is zero. Machines, operators and materials are assumed to be always available. No absence occurs. Any part operation is performed by following the pre-determined sequence according to the machine availability. Machine and part transmissions take zero time. The number of cells is constant and pre-determined. Upper and lower bounds of capacity of a cell are constant and pre-determined.

\section{Notation}

\section{Indices}

$\begin{array}{ll}\mathrm{i} & \text { index for the part types } \quad 1 \leq i \leq n \\ \mathrm{j} & \text { operation index required by parts } 0 \leq j \leq n_{i} \\ \mathrm{k} & \text { index for the machine types } 0 \leq k \leq m \\ \mathrm{l} & \text { position index in the operations sequence } 0 \leq l \leq l_{i} \\ \mathrm{c} & \text { index for the cells }\end{array}$

\section{Parameters}

$O_{i j} \quad \mathrm{j}^{\text {th }}$ operation of part $\mathrm{i}$

$p_{i j k} \quad$ standard time to process $O_{i j}$

$a_{i j k} \quad\left\{\begin{array}{l}1, \text { the operation } O_{i j} \text { is required processing on machine } \mathrm{k} \\ 0, \text { else }\end{array}\right.$

M a large positive number

Max_m maximum number of machines in a cell

Max_p maximum number of parts in a cell

Decision Variables

$\mathrm{x}_{\mathrm{i}, \mathrm{j}, \mathrm{k}, \mathrm{l}, \mathrm{c}}=\left\{\begin{array}{l}1, \text { if } \mathrm{O}_{\mathrm{ij}} \text { is processed on machine } \mathrm{k} \text { in the } l^{\text {th }} \text { position in cell c } \\ 0, \text { else }\end{array}\right.$

$z_{k, c}=\left\{\begin{array}{l}1, \text { if } \mathrm{k} \text { type of machine is allocated to cell c } \\ 0, \text { else }\end{array}\right.$

$y_{i, c}=\left\{\begin{array}{l}1, \text { if } \mathrm{i} \text { type of part is assigned to cell } \mathrm{c} \\ 0, \text { else }\end{array}\right.$

$t_{i, j} \quad$ starting time of $O_{i j}$

$\mathrm{Tm}_{k, l} \quad$ start of working time for machine $\mathrm{k}$ in the $l^{\mathrm{th}}$ order

Objective Functions and Constraints

$\operatorname{Min} Z_{o b j}=\sum_{i} \sum_{j} \sum_{k} \sum_{l} \sum_{c} x_{i, j, k, l, c} * z_{k, c} *\left(1-y_{i, c}\right)+C_{\max }$

$\sum_{k} \sum_{l} \sum_{c} x_{i, j, k, l, c}=1$ 


$$
\begin{aligned}
& \sum_{i} \sum_{j} x_{i, j, k, l, c} \leq 1 \\
& \sum_{l} \sum_{c} x_{i, j, k, l, c} \leq a_{i, j, k} \\
& t_{i, j+1} \geq t_{i, j}+\sum_{k} \sum_{l} x_{i, j, k, l, c} * p_{i, j, k} \quad \forall i, j<n_{j}, c \\
& T m_{k, l+1} \geq T m_{k, l}+\sum_{i} \sum_{j} x_{i, j, k, l, c} * p_{i, j, k} \quad \forall k, l<l_{i}, c \\
& T m_{k, l} \leq t_{i, j}+M *\left(1-x_{i, j, k, l, c}\right) \quad \forall i, j, k, l, c \\
& T_{k, l} \geq t_{i, j}-M *\left(1-x_{i, j, k, l, c}\right) \quad \forall i, j, k, l, \mathrm{c} \\
& C_{\text {max }} \geq t_{i, j}+\sum_{k} \sum_{l} x_{i, j, k, l, c} * p_{i, j, k} \quad \forall i, j, c \\
& \sum_{c} z_{k, c}=1 \\
& \sum_{k} z_{k, c} \geq 1 \\
& \sum_{k} z_{k, c} \leq \text { Max_m } \\
& \sum_{c} y_{i, c}=1 \\
& \sum_{i} y_{i, c} \geq 1 \\
& \sum_{i} y_{i, c} \leq \operatorname{Max} \_p_{-} \\
& x_{i, j, k, l, c} \leq a_{i, j, k} * z_{k, c} \\
& \begin{array}{ll}
z_{k, c}, y_{i, c}, x_{i, j, k, l, c} \in\{0,1\} & \forall k, \mathrm{c} \forall i, \mathrm{c} \\
& \forall i, j, k, l, \mathrm{c}
\end{array} \\
& C_{\text {max }}, Z_{o b j}, T m_{k, l}, t_{i, j} \geq 0 \quad \forall k, l \forall i, \mathrm{j}
\end{aligned}
$$


The scalarized objective function for minimizing EEs in cells and the makespan of the jobs is shown in equation (1). Constraint (2) ensures each operation of a part is assigned to one cell and only one position of all available machines. Constraint (3) defines the operations on machine sets. Constraint (4) guarantees each operation is processed on the pre-determined machines. Constraint (5) ensures the precedence relationships between the operation starting times. Constraint (6) guarantees each machine position can be occupied depending on the fulfillment of preceding positions of the machines. Constraints (7-8) ensure an operation can be assigned to one position of a machine when the machine is idle. Constraint (9) determines the makespan of operations by considering last completed time for all operations. Constraint (10) guarantees one machine must be assigned to only one cell. Constraints (11-12) ensure upper and lower bounds for assigning machines to cells. Constraint (13) guarantees each part is allocated to one cell. Constraints (14-15) ensure upper and lower bounds for assigning parts to cells. Constraint (16) guarantees that each part operation can be done only in the cell relevant machine assigned. Constraint (17) illustrates the binary decision variables and constraint (18) illustrates the continuous decision variables used in the model.

\section{Linearization}

The proposed model is non-linear and auxiliary binary variables $\left(F_{i, j, k, l, c}, S_{i, j, k, l, c}\right)$ are used to linearize the non-linear objective function terms that are the multiplication of binary variables and described as follows: $F_{i, j, k, l, c}=x_{i, j, k, l, c} * z_{k, c}$ and $S_{i, j, k, l, c}=x_{i, j, k, l, c} * z_{k, c} * y_{i, c}$. The following additional constraints are used to linearize the whole objective function.

$$
\begin{array}{lc}
x_{i, j, k, l, c}+z_{k, c} \geq 2 * F_{i, j, k, l, c} & \forall i, j, k, l, c \\
x_{i, j, k, l, c}+z_{k, c} \leq 1+F_{i, j, k, l, c} & \forall i, j, k, l, c \\
x_{i, j, k, l, c}+z_{k, c}+y_{i, c} \geq 3 * S_{i, j, k, l, c} & \forall i, j, k, l, c \\
x_{i, j, k, l, c}+z_{k, c}+y_{i, c} \leq 2+S_{i, j, k, l, c} & \forall i, j, k, l, c \\
\sum_{i} \sum_{j} \sum_{k} \sum_{l} \sum_{c}\left(F_{i, j, k, l, c}-S_{i, j, k, l, c}\right)=E E & \\
F_{i, j, k, l, c}, S_{i, j, k, l, c} \in\{0,1\} & \forall i, j, k, l, c
\end{array}
$$

Finally, EE part is normalized by dividing the number of EEs by the total number of operations. Maximum completion time is normalized by dividing maximum completion time by the probable worst maximum completion time value $\left(C_{\max }^{*}\right)$. In order to find the $C_{\max }^{*}$, the following procedure is used. By using the integrated proposed model, first find the schedule that minimizes EEs by minimizing EE objective in the model. Then, find the corresponding value for $C_{\max }^{*}$.

Finally, the ultimate linearized model is obtained via the generated normalized objective function in Eq. (25) and subject to constraints (2-24),

$$
\operatorname{Min} Z=\frac{E E}{\text { Total number of operations }}+\frac{C_{\max }}{C_{\max }^{*}} .
$$

\section{MODEL ANALYSIS AND NUMERICAL CALCULATIONS}

The number of variables and constraints in the proposed model are reported in Table 2 and Table 3 . The data set are obtained by adding cell aspect to the Fattahi et al. [39] FJSS problem. An example of the driven new problem is the name of SFJSCF-7, which is referred to as "SFJS7" in the literature. 
Table 2. The number of variables in the linear model

\begin{tabular}{lccc}
\multicolumn{4}{c}{ (Example problem SFJSCF_7 $i=3, j=3, k=5, c=3, l=4)$} \\
\hline Variables & Indices & Count & $\begin{array}{c}\text { Results for numerical } \\
\text { example }\end{array}$ \\
\hline$z_{k c}$ & $k, c$ & $k^{*} c$ & 15 \\
$y_{i c}$ & $i, c$ & $i^{*} c$ & 9 \\
$x_{i j k l c}$ & $i, j, k, l, c$ & $i^{*} j^{*} k^{*} l^{*} c$ & 540 \\
$S_{i j k l c}$ & $i, j, k, l, c$ & $i^{*} j^{*} k^{*} l^{*} c$ & 540 \\
$F_{i j k l c}$ & $i, j, k, l, c$ & $i^{*} j^{*} k^{*} l^{*} c$ & 540 \\
$t_{i j}$ & $i, j$ & $i^{*} j$ & 9 \\
$T m_{k l}$ & $k, l$ & $k^{* l}$ & 20 \\
$C_{e n b}$ & - & 1 & 1 \\
$H D E$ & - & 1 & 1 \\
$Z_{a m a c}$ & - & 1 & 1 \\
Total number of variables: $3 *\left(i * \mathrm{j} * \mathrm{k}^{*} 1 * \mathrm{c}\right)+\mathrm{c}^{*}(\mathrm{i}+\mathrm{k})+\mathrm{i}^{*} \mathrm{j}+\mathrm{k} * 1+3$ & 1676 \\
\hline
\end{tabular}

Table 3. The number of constraints in the linear model

\begin{tabular}{|c|c|c|c|c|c|c|c|}
\hline Cons. & Indices & Count & $\begin{array}{l}\text { Results for } \\
\text { numerical } \\
\text { example }\end{array}$ & Cons. & Indices & Count & $\begin{array}{l}\text { Results for } \\
\text { numerical } \\
\text { example }\end{array}$ \\
\hline 2 & $i, j$ & $i * j$ & 9 & 13 & $i$ & $i$ & 3 \\
\hline 3 & $k, l, c$ & $k * l * c$ & 60 & 14 & $c$ & $c$ & 3 \\
\hline 4 & $i, j, k$ & $i * j * k$ & 45 & 15 & $c$ & $c$ & 3 \\
\hline 5 & $i, j, c$ & $i *(j-1) * c$ & 18 & 16 & $i, j, k, l, c$ & $i * j * k * l * c$ & 540 \\
\hline 6 & $k, l, c$ & $k *(l-1) * c$ & 45 & 19 & $i, j, k, l, c$ & $i * j * k * l * c$ & 540 \\
\hline 7 & $i, j, k, l, c$ & $i * j * k * l * c$ & 540 & 20 & $i, j, k, l, c$ & $i * j * k * l * c$ & 540 \\
\hline 8 & $i, j, k, l, c$ & $i * j * k * l * c$ & 540 & 21 & $i, j, k, l, c$ & $i * j * k * l * c$ & 540 \\
\hline 9 & $i, j, c$ & $i^{*} j^{*} c$ & 27 & 22 & $i, j, k, l, c$ & $i * j * k * l * c$ & 540 \\
\hline 10 & $k$ & $k$ & 5 & 24 & - & 1 & 1 \\
\hline 11 & $c$ & $c$ & 3 & 25 & - & 1 & 1 \\
\hline 12 & $c$ & $c$ & 3 & & & & \\
\hline \multicolumn{7}{|c|}{$\begin{array}{l}\text { Total number of equations and constraints: } \\
2+7 *(i * j * k * 1 * c)+i * j *(1+\mathrm{k}+\mathrm{c})+\mathrm{k} *(1 * \mathrm{c}+1+(l-1) * c)+4 * \mathrm{c}+\mathrm{i}+i *(j-1) * c\end{array}$} & 4006 \\
\hline
\end{tabular}

First instance, "SFJS7" problem includes 3 jobs, 3 operations for each job and 5 machines. In this case, the cell size is assumed to be 3 . Table 4 shows order of operations, machine alternatives and part operation durations.

Table 4. Instance 1 (a three-job, five-machine FJSP)

\begin{tabular}{clll}
\hline & \multicolumn{3}{c}{ Operation } \\
\cline { 2 - 4 } Job & \multicolumn{1}{c}{2} & \multicolumn{1}{c}{3} \\
\hline 1 & $m_{1}=117$ & $m_{2}=130$ & $m_{4}=150$ \\
& $m_{2}=125$ & $m_{4}=140$ & $m_{5}=160$ \\
\cline { 2 - 4 } 2 & $m_{1}=214$ & $m_{2}=66$ & $m_{3}=65$ \\
& $m_{3}=150$ & $m_{3}=55$ & $m_{5}=78$ \\
\cline { 2 - 4 } 3 & $m_{1}=87$ & $m_{3}=80$ & $m_{4}=190$ \\
& $m_{2}=62$ & $m_{4}=70$ & $m_{5}=100$ \\
\hline
\end{tabular}

According to Table 4, the first operation of job 1 can be processed in the first machine in 117 units of time or in second machine in 125 units of time, and so on. Although there exist equal number of operations for 
each part, the model can produce solution for different number of operations for each part. Additionally, the size of alternative machine set can be different for each part operation.

The proposed integrated CF and CPS model has been coded in GAMS 24.2.1 and solved by CPLEX solver. Test problems are run on PC with Intel(R) Core(TM) i5-330 CPU, $3.2 \mathrm{GHz}$ processor and 8 GB RAM. For this small sized example, the minimum number of machines and parts that can be assigned to a cell is "1" and maximum "2". The results regarding the part and machine assignments to the cells show that the first and the second machines and also first job are assigned to the first cell. Fourth and fifth machines and the third job is assigned to the second cell. Finally, third machine and the second job are assigned to the third cell. CF matrices (Table 5) show the assignments of parts to the cells.

Table 5. A solution matrix for the instance 1

\begin{tabular}{cccc|c|c|c|}
\cline { 2 - 6 } & \multicolumn{5}{c}{ Machines } \\
\hline Parts & 1 & 2 & 4 & 5 & 3 \\
\cline { 2 - 6 } 1 & 1 & 2 & 3 & & \\
3 & & 1 & 2 & 3 & \\
\cline { 2 - 6 } 2 & & & & & $1,2,3$ \\
\hline
\end{tabular}

The first and the second operations of the first job are assigned to the first and the second machines in the first cell, while third operation of the first job is assigned to the forth machine in the second cell. In a similar way, while first operation of the third job will be processed in the second machine in the first cell, second and the third operations of the third job will be processed in the fourth and the fifth machines in the second cell. Finally, all operations of the second job will be processed in the third machine in the third cell. The "1"s outside the cells will constitute the EEs. In this case, there exist 2 EEs. According to the GAMS 24.2.1 results, the schedule, and the Gantt chart are seen in Figure 1 and Figure 2, respectively and makespan is 397 units of time. Finally, the objective function consisting makespan and the EE is equal to 399.

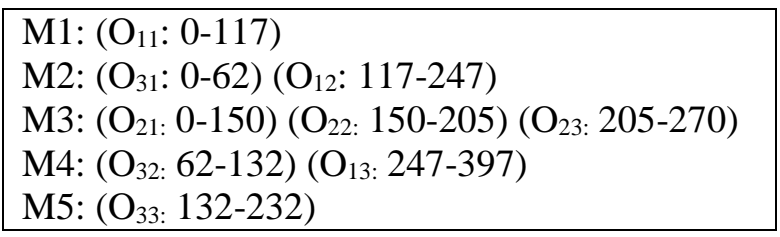

Figure 1. Schedule obtained for instance 1

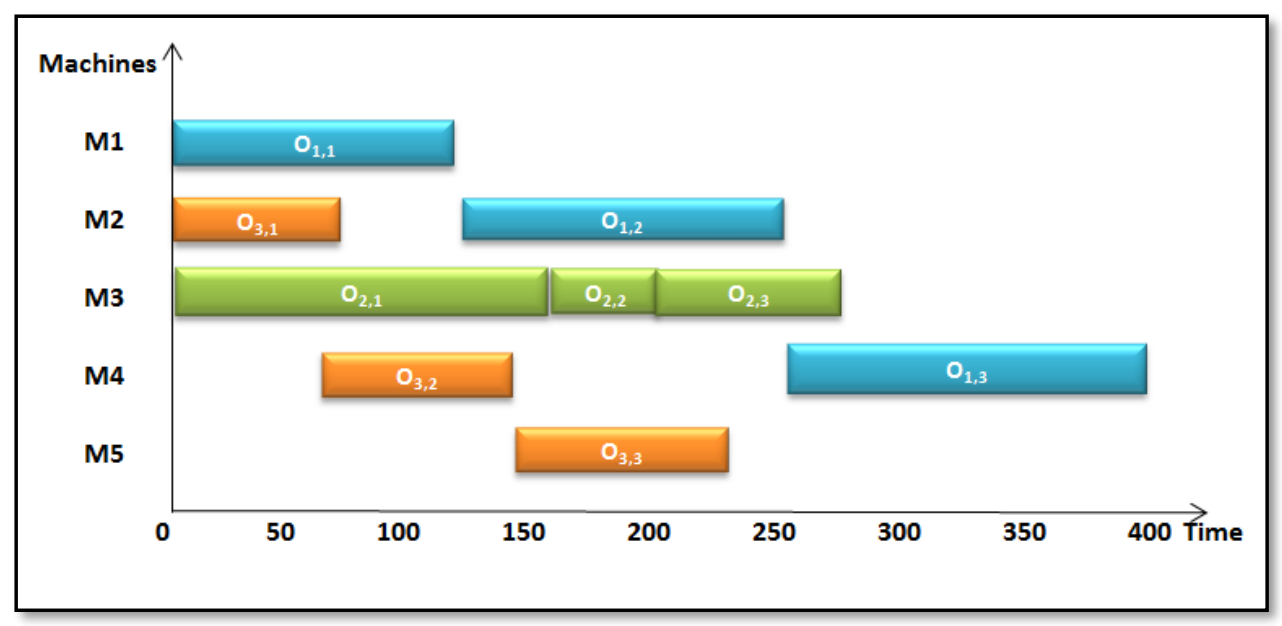

Figure 2. Gantt chart of solution for instance 1 
Second instance, the "SFJS10" problem from Fattahi et al. [39] has also considered for benchmarking. The problem includes 4 jobs, 5 machines and 3 operations for each job. In this case, the cell size is assumed to be 3. Order of operations, machine alternatives and part operations durations are shown in Table 6.

Table 6. Instance 2 (a four-job, five-machine FJSP)

\begin{tabular}{clll}
\hline \multicolumn{4}{c}{ Operations } \\
\hline Job & 1 & 2 & 3 \\
\cline { 2 - 4 } 1 & $m_{1}=147$ & $m_{2}=130$ & $m_{1}=150$ \\
& & $m_{4}=140$ & $m_{3}=160$ \\
\cline { 2 - 4 } 2 & $m_{1}=214$ & $m_{2}=66$ & $m_{5}=178$ \\
& $m_{3}=150$ & $m_{3}=87$ & \\
\cline { 2 - 4 } 3 & $m_{1}=87$ & $m_{3}=180$ & $m_{4}=190$ \\
& $m_{2}=62$ & & $m_{5}=100$ \\
\cline { 2 - 4 } 4 & $m_{1}=87$ & $m_{5}=173$ & $m_{3}=136$ \\
& $m_{2}=65$ & & $m_{4}=145$ \\
\hline
\end{tabular}

According to Table 6, the first operation of job 1 can be processed in the first machine in 147 units of time, and so on. For this small sized example, the minimum number of machines and parts that can be assigned to a cell is "1" and maximum "2". The results regarding the assignment of parts and machines to the cells show that the fifth machine and also the forth job are assigned to the cell 1 . The first and the forth machines and the first job is assigned to second cell. Finally, the second and the third machines and the second and the third jobs are assigned to the third cell. CF matrices (Table 7) show the assignments of parts to cells.

Table 7. A solution matrix for the instance 2

\begin{tabular}{ccc|c|c|c|}
\cline { 2 - 5 } & \multicolumn{5}{c}{ Machines } \\
\hline Parts & 5 & 1 & 4 & 2 & 3 \\
4 & 2 & & & 1 & 3 \\
\cline { 2 - 6 } 1 & & 1 & 2,3 & & \\
2 & 3 & & & 2 & 1 \\
3 & 3 & & & 1 & 2 \\
\hline
\end{tabular}

According to Table 7, the "1"s outside the cells will constitute the EE. There are 4 EEs for this solution. According to the GAMS 24.2.1 results, the schedule and the Gantt chart are seen in Figure 3 and Figure 4, respectively and makespan is 516 units of time.

M1: $\left(\mathrm{O}_{11}: 0-147\right)$

M2: $\left(\mathrm{O}_{41}: 0-65\right)\left(\mathrm{O}_{31}: 65-127\right)\left(\mathrm{O}_{22}: 150-216\right)$

M3: $\left(\mathrm{O}_{21}: 0-150\right)\left(\mathrm{O}_{32}: 150-330\right)\left(\mathrm{O}_{43:}: 330-466\right)$

M4: $\left(\mathrm{O}_{12}: 147-287\right)\left(\mathrm{O}_{13:}\right.$ 287-437)

M5: $\left(\mathrm{O}_{42}\right.$ : 65-238) $\left(\mathrm{O}_{23}\right.$ : 238-416) $\left(\mathrm{O}_{33}\right.$ : 416-516)

Figure 3. Schedule obtained for instance 2 


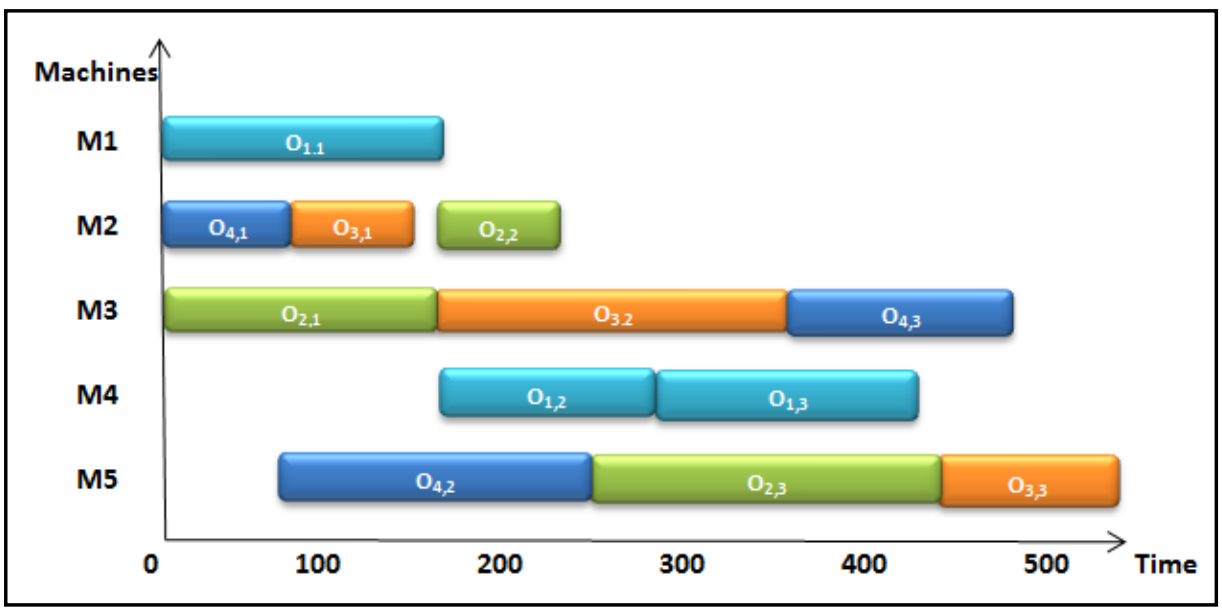

Figure 4. Gantt chart of solution for instance 2

Literature test problems derived from Fattahi et al. [39] and B\&B results for SFJSCF are presented in Table 8. The success of this method for small-sized problems is to offer the minimum completion time in the literature results by also taking into account the minimization of EEs.

To illustrate that the integrated approach can produce beneficial results, the problem is addressed in three phases: sub-model_1, sub-model_2 and integrated model. In the solution with sub-model 1, the integrated mathematical model developed has been solved for the first objective $\mathrm{C}_{\max }$, and the results obtained for $\mathrm{C}_{\max }$ and EE have been recorded. Similarly, the model integrated with sub-model_2 has been solved taking into account the second objective EE and the results were recorded for both objectives. On the integrated model, the solutions have been investigated taking into consideration the objective function in Eq. (25). Since, there is no publication to compare the results of the integrated objective function proposed in this study and in order to show that the proposed integrated model is superior to the models in which the individual results are obtained, the formulas expressing the deviations have been used (Eq. (26) and Eq. (27))

$$
\begin{aligned}
& \text { Dev.Sub } b_{\text {model } 1}=\frac{o b j_{1_{\text {integratedmodel }}}-O b j_{1_{\text {submodel }_{1}}}}{100}+\frac{O b j_{\text {integratedmodel }}-O b j_{\text {submodel }_{1}}}{100},
\end{aligned}
$$

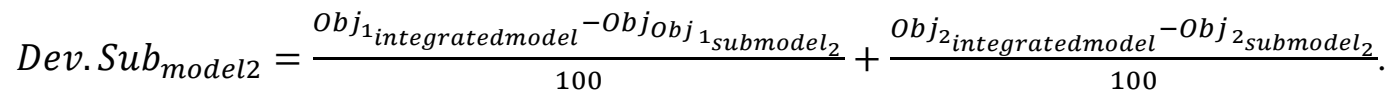

The objective function in Eq. (25) has an integrated structure and the two sub-objectives are combined in a single function. In all of the small size problems mentioned in this study, global optimal results could be obtained using GAMS 24.2.1 software CPLEX solver. As shown in Table 8, deviations are either "0" or negative. The "0" and the negative results obtained with these functions showed the superiority of the proposed technique over the models producing solutions by taking into account the objectives individually. This can be interpreted as showing that the method used can achieve better objective functions than the one-object-oriented methods. The solution times of all three models are very close to each other in small size test problems. By solving the problem with the integrated approach, the problem can be solved with as good compromise as possible by taking into account the purposes of scheduling and CF decisions. As shown in the comparison table, it is possible to handle the problem of CF problem by providing zero deviation in the scheduling aspect. The results obtained with the purpose of makespan are the best values in FJSS literature [39]. As stated in the literature and also seen in the results of this study, the integrated models present superior performance [3, 4]. 
Table 8. Literature test problems derived from Fattahi et al. [39] and B\&B results for SFJSCF

\begin{tabular}{|c|c|c|c|c|c|c|c|c|c|}
\hline \multirow[t]{2}{*}{ Problem } & \multirow{2}{*}{$\begin{array}{c}\text { Size (part, } \\
\text { operation, } \\
\text { machine, } \\
\text { cell) }\end{array}$} & \multirow[t]{2}{*}{$\begin{array}{l}\text { \# integer, } \\
\text { total } \\
\text { variables }\end{array}$} & \multirow[t]{2}{*}{$\begin{array}{l}\text { Total const. } \\
\quad \text { and } \\
\text { equations }\end{array}$} & \multirow{2}{*}{$\begin{array}{c}\text { Optimized sub- } \\
\text { model for } \\
\text { Cmax }\end{array}$} & \multirow{2}{*}{$\begin{array}{l}\text { Optimized sub- } \\
\text { model for } \\
\text { EE } \\
\text { (Cmax, EE) }\end{array}$} & \multicolumn{2}{|c|}{ Integrated Model Solutions } & \multicolumn{2}{|c|}{$\begin{array}{l}\text { Comparison with sub-models } \\
\text { and the integrated approach } \\
\text { solutions }\end{array}$} \\
\hline & & & & & & $\begin{array}{c}\mathrm{CPU} \\
\text { time (s) }\end{array}$ & (Cmax, EE) & Sub model-1 & Sub-model-2 \\
\hline SFJSCF_1 & $(2,2,2,2)$ & 200,215 & 514 & $(66,4)$ & $(130,0)$ & 0.04 & $(66,0)$ & -0.04 & -0.64 \\
\hline SFJSCF_2 & $(2,2,2,2)$ & 152,165 & 394 & $(107,0)$ & $(107,0)$ & 0.04 & $(107,0)$ & 0 & 0 \\
\hline SFJSCF_3 & $(3,2,2,2)$ & 370,389 & 927 & $(221,5)$ & $(298,0)$ & 2 & $(221,1)$ & -0.04 & -0.76 \\
\hline SFJSCF_4 & $(3,2,2,2)$ & 442,463 & 1103 & $(355,5)$ & $(430,0)$ & 4 & $(355,1)$ & -0.04 & -0.74 \\
\hline SFJSCF_5 & $(3,2,2,2)$ & 442,463 & 1103 & $(119,3)$ & $(134,0)$ & 10 & $(119,3)$ & 0 & -0.12 \\
\hline SFJSCF_6 & $(3,3,2,2)$ & 1308,1344 & 3196 & $(320,4)$ & $(367,0)$ & 19 & $(320,0)$ & -0.04 & -0.47 \\
\hline SFJSCF_7 & $(3,3,5,3)$ & 1644,1676 & 4006 & $(397,6)$ & $(415,0)$ & 4 & $(397,2)$ & -0.04 & -0.16 \\
\hline SFJSCF_8 & $(3,3,4,3)$ & 1641,1673 & 3999 & $(253,6)$ & $(313,2)$ & 369 & $(253,3)$ & -0.03 & -0.59 \\
\hline SFJSCF_9 & $(3,3,3,3)$ & 1476,1506 & 3602 & $(210,7)$ & $(370,2)$ & 3 & $(210,4)$ & -0.03 & -1.58 \\
\hline SFJSCF_10 & $(4,3,5,3)$ & 2187,2222 & 5300 & $(516,7)$ & $(1121,3)$ & 103 & $(\mathbf{5 1 6}, 4)$ & -0.03 & -6.04 \\
\hline
\end{tabular}

EE: exceptional element 


\section{CONCLUSIONS}

In this paper, a new multi objective mathematical model is proposed aiming at simultaneous optimization of part scheduling and CF problems in CMS environment. This study has emerged from the fact that the optimization of the objectives one by one is insufficient in optimizing the overall system performance and it is contributed to the literature in terms of being a model that considers objectives together. Because of its complex nonlinear structure, the auxiliary variables have been added to linearize the proposed model. The applicability of the linearized model is verified and demonstrated on numerical examples. Additionally, the proposed model is tested on the test problems. The results relating to the developed model confirms that the small sized problems can easily be solved using GAMS 24.2.1 software and the best results can easily be obtained in very short computational times. The computational results show that the proposed integrated model is very effective to improve the overall system performance when compared to the optimization of the considered objectives separately.

On the other hand, it should be noted that the times to reach the optimal solutions are rapidly growing together with the growing sizes of the studied problem because of its NP-hard structure. So, in a future research, the well-known heuristic methods like simulated annealing, tabu search or genetic algorithms can be applied for medium or large sized cases and, their results can be compared in more complicated CMS problems along with the scheduling objectives like the ones including setup times. Another future study may research pareto optimal solutions instead of using scalarization technique.

\section{ACKNOWLEDGEMENT}

This study was supported by the Eskisehir Osmangazi University Scientific Research Projects Committee under project number 201515A207 (2015-787).

\section{CONFLICTS OF INTEREST}

No conflict of interest was declared by the authors.

\section{REFERENCES}

[1] Singh, N. and Rajamani, D., Cellular manufacturing systems: design, planning and control. Chapman \& Hall, (1996).

[2] Ang, D., "Exceptional Elements Framework in Group Technology", Simulation, 17 (18), (2011).

[3] Arkat, J., Farahani, M. H., Hosseini, L., "Integrating cell formation with cellular layout and operations scheduling", The International Journal of Advanced Manufacturing Technology, 61(5): 637-647, (2012).

[4] Wu, X., Chu, C. H., Wang, Y., Yue, D., "Genetic algorithms for integrating cell formation with machine layout and scheduling. Computers \& Industrial Engineering", 53(2): 277-289, (2007).

[5] Wang, X., Tang, J., Yung, K.L., "Optimization of the multi-objective dynamic cell formation problem using a scatter search approach", The International Journal of Advanced Manufacturing Technology, 44(3-4): 318-329, (2009).

[6] Deljoo, V., Mirzapour Al-e-hashem, S. M. J., Deljoo, F., Aryanezhad, M. B., "Using genetic algorithm to solve dynamic cell formation problem", Applied Mathematical Modelling, 34(4): 1078-1092, (2010).

[7] Brown, J.R., "A capacity constrained mathematical programming model for cellular manufacturing with exceptional elements", Journal of Manufacturing Systems, 37: 227-232, 
(2015).

[8] Buruk Sahin, Y. and Alpay, S., "A metaheuristic approach for a cubic cell formation problem", Expert Systems with Applications, 65: 40-51, (2016).

[9] Chang, C. C., Wu, T. H., Wu, C. W., "An efficient approach to determine cell formation, cell layout and intracellular machine sequence in cellular manufacturing systems", Computers \& Industrial Engineering, 66(2): 438-450, (2013).

[10] Mahdavi, I., Teymourian, E., Baher, N. T., Kayvanfar, V., "An integrated model for solving cell formation and cell layout problem simultaneously considering new situations", Journal of Manufacturing Systems, 32(4): 655-663, (2013).

[11] Bagheri, M., Bashiri, M., "A new mathematical model towards the integration of cell formation with operator assignment and inter-cell layout problems in a dynamic environment", Applied Mathematical Modelling, 38(4): 1237-1254, (2014).

[12] Mehdizadeh, E., Rahimi, V., "An integrated mathematical model for solving dynamic cell formation problem considering operator assignment and inter/intra cell layouts", Applied Soft Computing, 42: 325-341, (2016).

[13] Sadeghi, S., Forghani, M. A., Seidi, M., "Integrated dynamic cell formation with operator assignment and inter-cell layout problems: A mathematical model", Proceedings of the Institution of Mechanical Engineers, Part B: Journal of Engineering Manufacture, 231(9): 1658-1669, (2015).

[14] Arkat, J., Farahani, M. H., Hosseini, L., "Integrating cell formation with cellular layout and operations scheduling", The International Journal of Advanced Manufacturing Technology, 61(58): 637-647, (2012).

[15] Halat, K., Bashirzadeh, R., "Concurrent scheduling of manufacturing cells considering sequencedependent family setup times and intercellular transportation times", The International Journal of Advanced Manufacturing Technology, 77(9-12): 1907-1915, (2015).

[16] Frazier, G., "An evaluation of group scheduling heuristics in a flow-line manufacturing cell", International Journal of Production Research, 34(4): 959-976, (1996).

[17] Hendizadeh, S. H., Faramarzi, H., Mansouri, S. A., Gupta, J. N., ElMekkawy, T. Y., "Metaheuristics for scheduling a flowline manufacturing cell with sequence dependent family setup times", International journal of production economics, 111(2): 593-605, (2008).

[18] Solimanpur, M., Elmi, A., "A tabu search approach for group scheduling in buffer-constrained flow shop cells", International Journal of Computer Integrated Manufacturing, 24(3): 257-268, (2011).

[19] Sridhar, J., Rajendran, C., "A genetic algorithm for family and job scheduling in a flowline-based manufacturing cell", Computers \& Industrial Engineering, 27(1-4): 469-472, (1994).

[20] Mahmoodi, F., Dooley, K. J., Starr, P. J., "An investigation of dynamic group scheduling heuristics in a job shop manufacturing cell", The International Journal of Production Research, 28(9): 16951711, (1990).

[21] Ruben, R. A., Mosier, C. T., Mahmoodi, F., "A comprehensive analysis of group scheduling heuristics in a job shop cell", The International Journal of Production Research, 31(6): 1343-1369, (1993). 
[22] Elmi, A., Solimanpur, M., Topaloglu, S., Elmi, A., "A simulated annealing algorithm for the job shop cell scheduling problem with intercellular moves and reentrant parts", Computers \& industrial engineering, 61(1): 171-178, (2011).

[23] Mahdavi, I., Paydar, M. M., Solimanpur, M., Heidarzade, A., "Genetic algorithm approach for solving a cell formation problem in cellular manufacturing", Expert Systems with Applications, 36(3): 6598-6604, (2009).

[24] Ozguven, C., Yavuz, Y., Ozbakir, L., "Mixed integer goal programming models for the flexible job-shop scheduling problems with separable and non-separable sequence dependent setup times", Applied Mathematical Modelling, 36(2): 846-858, (2012).

[25] Fattahi, P., Jolai, F., Arkat, J., "Flexible job shop scheduling with overlapping in operations", Applied Mathematical Modelling, 33(7): 3076-3087, (2009).

[26] Moradi, E., Ghomi, S.F., Zandieh, M., "Bi-objective optimization research on integrated fixed time interval preventive maintenance and production for scheduling flexible job-shop problem", Expert systems with applications, 38(6): 7169-7178, (2011).

[27] Papaioannou, G. Wilson, J.M., "Fuzzy extensions to Integer Programming models of cellformation problems in machine scheduling", Annals of Operations Research, 166(1): 163-181, (2009).

[28] Wang, X., Tang, J., Yung, K. L., "A scatter search approach with dispatching rules for a joint decision of cell formation and parts scheduling in batches", International Journal of Production Research, 48(12): 3513-3534, (2010).

[29] Ghezavati, V., Saidi-Mehrabad, M., "Designing integrated cellular manufacturing systems with scheduling considering stochastic processing time", The International Journal of Advanced Manufacturing Technology, 48(5-8): 701-717, (2010).

[30] Kesen, S. E., Das, S. K., Güngör, Z., "A genetic algorithm based heuristic for scheduling of virtual manufacturing cells (VMCs)", Computers \& Operations Research, 37(6): 1148-1156, (2010).

[31] Dalfard, V.M., "New mathematical model for problem of dynamic cell formation based on number and average length of intra and intercellular movements", Applied Mathematical Modelling, 37(4): 1884-1896, (2013).

[32] Tang, J., Yan, C., Wang, X., Zeng, C., "Using Lagrangian Relaxation Decomposition With Heuristic to Integrate the Decisions of Cell Formation and Parts Scheduling Considering Intercell Moves", Automation Science and Engineering, IEEE Transactions Automation Science and Engineering, 11(4): 1110-1121, (2014).

[33] Li, D., Meng, X., Li, M., \& Tian, Y., "An ACO-based intercell scheduling approach for job shop cells with multiple single processing machines and one batch processing machine", Journal of Intelligent Manufacturing, 27(2): 283-296, (2016).

[34] Rafiei, H., Rabbani, M., Gholizadeh, H., Dashti, H., "A novel hybrid SA/GA algorithm for solving an integrated cell formation-job scheduling problem with sequence-dependent set-up times", International Journal of Management Science and Engineering Management, 11(3): 134-142, (2016).

[35] Zeng, C., Tang, J., Yan, C., "Job-shop cell-scheduling problem with inter-cell moves and automated guided vehicles", Journal of Intelligent Manufacturing, 26(5): 845-859, (2015). 
[36] Deliktas, D., Torkul, O., Ustun, O., "A flexible job shop cell scheduling with sequence-dependent family setup times and intercellular transportation times using conic scalarization method", International Transactions in Operational Research, 26(6): 2410-2431, (2017).

[37] Feng, Y., Li, G., Sethi, S.P., "A three-layer chromosome genetic algorithm for multi-cell scheduling with flexible routes and machine sharing", International Journal of Production Economics, 196: 269-283, (2018).

[38] Lee, C. Y., Cheng, T. C. E., Lin, B. M. T., "Minimizing the makespan in the 3-machine assemblytype flowshop scheduling problem", Management Science, 39(5): 616-625, (1993).

[39] Fattahi, P., Mehrabad, M. S., Jolai, F., "Mathematical modeling and heuristic approaches to flexible job shop scheduling problems", Journal of Intelligent Manufacturing, 18(3): 331-342, (2007).

[40] Demir, Y., İşleyen, S. K., "Evaluation of mathematical models for flexible job-shop scheduling problems", Applied Mathematical Modelling, 37(3): 977-988, (2013). 